\title{
Izabela Gabryelewicz*
}

\section{BADANIA ANKIETOWE JAKO CZYNNIK WSPOMAGAJĄCY ZARZĄDZANIE BEZPIECZEŃSTWEM PRACY}

Z a r y s t r e ś c i: Według danych statystycznych główną przyczyna wypadków jest niewłaściwe zachowanie się pracownika. W analizie przyczyn wypadków mówi się o niskim poziome kultury bezpieczeństwa pracy. Zwiększenie poziomu kultury bezpieczeństwa wymaga zdiagnozowania stanu przedsiębiorstwa oraz identyfikacji słabych i mocnych stron organizacji. W tym celu potrzebne jest dobre narzędzie diagnostyczne np. ankieta. W artykule przedstawiono zasadę budowy ankiet, przedstawiono propozycję takiej ankiety oraz częściowe wyniki badań jakie uzyskano za pomocą autorskiej ankiety do badania poziomu klimatu bezpieczeństwa w przedsiębiorstwie.

S ło w a k 1 u c z o w e: badania ankietowe, bezpieczeństwo pracy, kultura bezpieczeństwa

K 1 a s y fik a cja J E L: L21

\section{WSTĘP}

Do pewnego czasu, bezpieczeństwo pracy, utożsamiano z systemami technicznymi, różnego rodzaju zabezpieczeniami technicznymi lub środkami ochrony indywidualnej lub zbiorowej. Jak się okazuje, często pomimo dużych nakładów na środki techniczne, w zakładach pracy nadal występują liczne awarie a bezpieczeństwo nie jest adekwatne do ponoszonych na nie nakładów. Uważa się, że tego przyczyną jest niska kultura bezpieczeństwa w organizacji. W tabeli 1 przedstawiono definicję kultury bezpieczeństwa oraz jej aspekty.

Seria awarii i katastrof, wyniki analiz po tych zdarzeniach, oraz dane statystyczne dotyczące przyczyn wypadków przy pracy sugerują, że w obecnych czasach coraz częściej przyczyną awarii jest tzw. czynnik ludzki. W Polsce także można wyciągnąć taki wniosek. Statystyki dotyczące przyczyn

\footnotetext{
* Adres do korespondencji: Izabela Gabryelewicz, Uniwersytet Zielonogórski, Wydział Mechaniczny, Zakład Mechaniki i Projektowania Maszyn, e-mail: igabryelewicz@wp.pl
} 
wypadków przy pracy, jednoznacznie wskazują, że zależnie od branży, około $50-70 \%$ wypadków jest spowodowane przez człowieka. Dość łatwo jest zidentyfikować uchybienia w technicznych środkach bezpieczeństwa lub w organizacji pracy. Trudniej jest zidentyfikować przyczyny popełniania zaniedbań z przyczyn ludzkich. I tutaj dużą role odgrywają badania nad kulturą bezpieczeństwa pracy i badania ankietowe nad klimatem bezpieczeństwa w organizacji.

Tabela 1. Trzy aspekty kultury bezpieczeństwa

\begin{tabular}{|c|c|c|}
\hline \multicolumn{3}{|c|}{$\begin{array}{l}\text { Kultura bezpieczeństwa } \\
\text { "Produkt indywidualnych i grupowych wartości, postaw, postrzegania, kompetencji i wzorów zachowań, } \\
\text { które określają zaangażowanie oraz styl zarzadzania bezpieczeństwem i zdrowiem organizacji” } \\
\text { ACSNI Human Factors Study Group, HSC (1993) }\end{array}$} \\
\hline $\begin{array}{c}\text { Aspekty psychologiczne } \\
\text { (Jak ludzie czują) }\end{array}$ & $\begin{array}{l}\text { Aspekty behawioralne } \\
\text { (Co ludzie robią) }\end{array}$ & $\begin{array}{l}\text { Aspekty sytuacyjne } \\
\text { (Co organizacja ma) }\end{array}$ \\
\hline $\begin{array}{l}\text { Co można opisać jako „klimat } \\
\text { bezpieczeństwa” organizacji, która skupia } \\
\text { się na indywidualnych i grupowych } \\
\text { poglądach, wartościach i postawach }\end{array}$ & $\begin{array}{l}\text { Działania i zachowania } \\
\text { zwiazzane z } \\
\text { bezpieczeństwem }\end{array}$ & $\begin{array}{l}\text { Zasady, procedury, przepisy, } \\
\text { struktura organizacji i } \\
\text { system zarządzania }\end{array}$ \\
\hline
\end{tabular}

Źródło: A review of safety culture and safety climate literature for the development of the safety culture inspection toolkit, Research Report 367, Prepared by Human Engineering for the Health and Safety Executive 2005, s.4

\section{BADANIA ANKIETOWE}

Wstępną analizę stanu poziomu kultury bezpieczeństwa w zakładzie pracy można dokonać za pomocą ankiety. Jednak aby taka ankieta spełniła swoją rolę musi być odpowiednio skonstruowana. W literaturze przedmiotu można znaleźć wiele definicji ,ankiety”. Kilka z nich przytoczono w tabeli 2.

Tabela 2. Definicja „,ankiety” według różnych autorów

\begin{tabular}{|c|l|}
\hline Autor & \multicolumn{1}{|c|}{ Definicja } \\
\hline Zaczyński, 1995 & $\begin{array}{l}\text { technika pośredniego zdobywania informacji przez pytania stawiane wybranym } \\
\text { osobom za pośrednictwem drukowanej listy pytań - kwestionariusza }\end{array}$ \\
\hline $\begin{array}{c}\text { Konarzewski, } \\
2000, \text { s.139 }\end{array}$ & $\begin{array}{l}\text { technika zbierania danych polegająca na planowym wypytywaniu badanego. } \\
\text { Podstawą ankiety jest kwestionariusz, czyli ustalona lista pytań; }\end{array}$ \\
\hline Pilch, Bauman, & $\begin{array}{l}\text { technika gromadzenia informacji polegajaca na wypełnianiu najczęściej } \\
\text { samodzielnie przez badanego specjalnych kwestionariuszy na ogół o wysokim } \\
\text { stopniu standaryzacji }\end{array}$ \\
\hline Łobocki, & $\begin{array}{l}\text { ankieta jest arkuszem z wydrukowanymi na nim pytaniami i wolnymi miejscami na } \\
\text { wpisywanie odpowiedzi lub też z gotowymi odpowiedziami, spośród których osoby } \\
\text { badane wybierają te, które uważają za prawidłowe. }\end{array}$ \\
\hline
\end{tabular}


Ankieta [Pilch, Bauman, 2001 s. 49] jest niezastąpiona jako narzędzie poznawania cech zbiorowości, faktów, opinii o zdarzeniach, danych liczbowych. Pełni ważną funkcję w początkowym etapie badań, gdy chcemy zdobyć wiedzę wyjściową, a miarę ogólną do przygotowania szczegółowych badań wywiadem lub za pomocą obserwacji. Niezależnie od przyjętej definicji, pytania zawarte w kwestionariuszu ankiety powinny być [Pilch, Bauman, 2001; Dudkiewicz, 2000, s. 87; Frankfort-Nachmias, 2004, s. 267; Mangione, 1991, s. 31; Kaczmarczyk, 2003, s. 173]:

- konkretne, jednoznaczne i zrozumiałe dla respondenta, krótkie i proste składniowo, pojedyncze,

- źródłem do testowania hipotez badawczych,

- nie sugerujące odpowiedzi,

- definiujące najważniejsze pojęcia,

- logicznie poukładane,

- skierowane do odpowiednich osób,

- bez podwójnych zaprzeczeń,

- bez fachowego żargonu.

Pomimo, że ankieta jest dobrym narzędziem badawczym, nie jest pozbawiona wad. Wady i zalety posługiwania się ankietą jako narzędziem badawczym przedstawiono $\mathrm{w}$ tabeli 3 .

Tabela 3. Wady i zalety posługiwania się ankietą jako narzędziem badawczym

\begin{tabular}{|l|c|}
\hline \multicolumn{1}{|c|}{ Zalety } & Wady \\
\hline - jest prostym i szybkim sposobem na & - wymagają zarówno dużego doświadczenia \\
zebranie dużej ilości danych dotyczące & badawczego, jak też i dobrego przygotowania \\
badanej zbiorowości, niekoniecznie & metodologicznego osoby przeprowadzającej badania \\
skupionej w jednym miejscu; & tego typu, \\
- dzięki standardowemu zestawowi & - nie pozwala dogłębnie zweryfikować badanego \\
pytań możliwe jest wielokrotne jej & problemu przez ograniczenia, jakie niosą ze sobą \\
powtarzanie, & zasady budowania „dobrego” kwestionariusza, \\
- sprzyja zachowaniu wysokiego stopnia & - ograniczony kontakt respondenta z ankieterem, \\
anonimowości, co pozytywnie wpływa & - trudno jest uzyskać 100\% zwrot ankiet, \\
na jakość odpowiedzi respondentów, & - naraża w wysokim stopniu badacza na brak \\
- ograniczona rola ankietera, co wpływa & odpowiedzi ze strony respondenta, \\
na brak błędów ankieterskich. & - respondent może wcześniej zapoznać się z całą listą \\
& pytań i udzielić odpowiedzi spójnych, ale nieszczerych \\
\hline
\end{tabular}

Źródło: Sołoma L., (2002), Metody i techniki badań socjologicznych, Wyd. Uniwersytetu Warmińsko-Mazurskiego, Olsztyn. Kisiel P., (2000), Spoleczne aspekty badań marketingowych. Wybrane problemy, Akademia Ekonomiczna w Krakowie, Kraków. 


\section{AUTORSKI KWESTIONARIUSZ ANKIETY}

W badaniach, ze względu na sposób przekazywania kwestionariusza ankiety wykorzystano dwa rodzaje ankiet: ankietę audytoryjną (wypełnianą podczas szkoleń) i ankietę rozdawaną. W badaniach tego typu bardzo ważna jest rzetelność i szczerość udzielanych odpowiedzi, dlatego ankiety były całkowicie anonimowe. Wyniki badań pochodzą z ankiety jednorazowej (celem było zbadanie poziomu kultury bezpieczeństwa na określony moment działalności przedsiębiorstwa), jednak w planach jest powtórzenie badań w celu sprawdzenia skuteczności wprowadzania działań na rzecz podnoszenia poziomu kultury bezpieczeństwa.

W ankiecie zastosowano pytania zamknięte dysjunktywne (które pozwalają na wybranie tylko jednej odpowiedzi). Do oceny pytań zastosowano pięciostopniową skalę Lickerta [Gabryelewicz, Sadłowska-Wrzesińska, Kowal, 2015]. Ankietę kończą pytania metryczkowe obejmujące podstawowe cechy

\section{Celem ankiety jest zapoznanie się z Twoimi poglądami na temat bezpieczeństwa w Twoim miejscu pracy. Twoje odpowiedzi są całkowicie anonimowe i poufne.}

\begin{tabular}{|c|c|c|c|c|c|c|}
\hline & & \multicolumn{5}{|c|}{ Przykładowe sposoby podawania odpowiedzi } \\
\hline & & $\begin{array}{l}\text { Zdecydowa } \\
\text { nie tak }\end{array}$ & $\begin{array}{l}\text { Raczej } \\
\text { tak }\end{array}$ & $\begin{array}{l}\text { Nie } \\
\text { wiem }\end{array}$ & $\begin{array}{l}\text { Raczej } \\
\text { nie }\end{array}$ & $\begin{array}{l}\text { Zdecydowa } \\
\text { nie nie }\end{array}$ \\
\hline & & \multicolumn{5}{|c|}{ Przy każdym pytaniu umieść tylko jeden znak $X$} \\
\hline 1 & Mój zakład pracy jest bezpieczny & $\square$ & $\mathbf{2}$ & $\square$ & $\square$ & $\square$ \\
\hline 2 & Mam zaufanie do kierownictwa & 50 & $\square$ & $\square$ & $\square$ & \\
\hline & & \multicolumn{5}{|c|}{$\begin{array}{l}\text { W przypadku umieszczenia znaku X w niewłaściwym polu, } \\
\text { zaczernij całe pole i umieść nowy znak X we właściwym polu }\end{array}$} \\
\hline
\end{tabular}

\begin{tabular}{|c|l|c|c|c|c|c|}
\cline { 3 - 6 } \multicolumn{2}{l|}{} & $\begin{array}{c}\text { Zdecyd } \\
\text { owanie } \\
\text { tak }\end{array}$ & $\begin{array}{c}\text { Raczej } \\
\text { tak }\end{array}$ & $\begin{array}{c}\text { Nie } \\
\text { wiem }\end{array}$ & $\begin{array}{c}\text { Raczej } \\
\text { nie }\end{array}$ & $\begin{array}{c}\text { Zdecyd } \\
\text { owanie } \\
\text { nie }\end{array}$ \\
\hline 1 & Znam zagrożenia na moim stanowisku pracy & $\square$ & $\square$ & $\square$ & $\square$ & $\square$ \\
\hline 2 & $\begin{array}{l}\text { Zdarza się, że podpisuję dokumenty z zakresu } \\
\text { bezpieczeństwa nie znając ich treści }\end{array}$ & $\square$ & $\square$ & $\square$ & $\square$ & $\square$ \\
\hline 3 & Wiem, jak się zachować w razie wypadku & $\square$ & $\square$ & $\square$ & $\square$ & $\square$ \\
\hline 4 & Przepisy bhp utrudniają pracę & $\square$ & $\square$ & $\square$ & $\square$ & $\square$ \\
\hline
\end{tabular}

Rysunek 1. Fragment ankiety do badania poziomu klimatu bezpieczeństwa

\section{CZĘŚCIOWE WYNIKI BADAŃ}

Analiza wyników badań pozwala zidentyfikować słabe i mocne strony badanego przedsiębiorstwa w aspekcie poziomu kultury bezpieczeństwa. $\mathrm{Na}$ wykresach przedstawiono zależność poziomu kultury bezpieczeństwa od stażu pracy pracownika. Analizę dokonano w dziewięciu kategoriach tematycznych, 
które odpowiadają desygnatom wysokiej kultury bezpieczeństwa.

W tabeli 4 przedstawiono strukturę badanych pracowników ze względu na ogólny staż pracy. Mężczyźni stanowią $88 \%$ badanych. Z czego $58 \%$ to pracownicy ze stażem pracy od 11 do 20 lat. Więc większość to pracownicy doświadczeniu, z długim stażem pracy. Można by sądzić, że będą to ludzie znający zasady bhp oraz szanujący własne i innych życie oraz zdrowie.

Tabela 4. Struktura grupy badanych osób - ogólny staż pracy

\begin{tabular}{|r|c|c|c|c|c|c|}
\hline \multirow{2}{*}{ Staż pracy } & \multicolumn{2}{|c|}{ Ogółem } & \multicolumn{2}{c|}{ Kobiet } & \multicolumn{2}{c|}{ Mężczyzn } \\
\cline { 2 - 7 } & $\begin{array}{c}\text { Liczba } \\
{[100]}\end{array}$ & $\%[100]$ & $\begin{array}{c}\text { Liczba } \\
{[12]}\end{array}$ & $\begin{array}{c}\% \\
{[12.00]}\end{array}$ & $\begin{array}{c}\text { Liczba } \\
{[88]}\end{array}$ & $\begin{array}{c}\% \\
{[88.00]}\end{array}$ \\
\hline do 2 lat & 5 & 5.00 & 2 & 2.00 & 3 & 3.00 \\
\hline od 3 do 5 lat & 5 & 5.00 & 1 & 1.00 & 4 & 4.00 \\
\hline od 6 do 10 lat & 8 & 8.00 & 1 & 1.00 & 7 & 7.00 \\
\hline od 11 do 15 lat & 33 & 33.00 & 4 & 4.00 & 29 & 29.00 \\
\hline od 16 do 20 lat & 32 & 32.00 & 3 & 3.00 & 29 & 29.00 \\
\hline powyżej 20 lat & 17 & 17.00 & 1 & 1.00 & 16 & 16.00 \\
\hline
\end{tabular}

Źródło: opracowanie własne

Wykres 1 przedstawia poziom klimatu bezpieczeństwa w zależności od ogólnego stażu pracy. Najniższy poziom prezentują pracownicy z najniższym stażem pracy. Pracownicy ci najsłabiej wypadają w dwóch kategoriach: IV. Stosunek do służb bhp (33\%) oraz VII. Stosunek do szkoleń z zakresu bhp (45\%). Wśród wszystkich grup pracowników, niezależnie od stażu pracy, najsłabsze wyniki uzyskano w kategorii VIII. Odporność na stres (najniższy wynik uzyskali pracownicy ze stażem pracy od 6 do 10 lat, najwyższy wynik mają pracownicy z najwyższym stażem pracy).

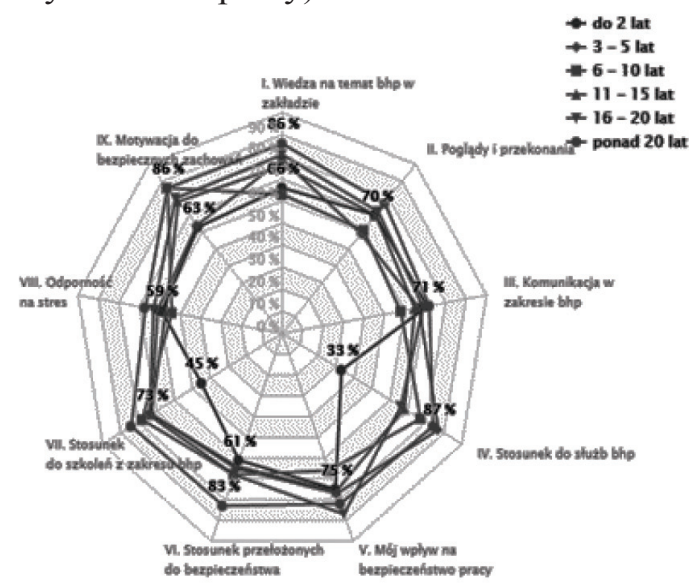

Wykres 1. Poziom klimatu bezpieczeństwa w zależności od ogólnego stażu pracy pracownika

Źródło: opracowanie własne 
W tabeli 5 zaprezentowano strukturę badanych pracowników ze względu na staż pracy w obecnym zakładzie pracy. Najliczniejszą grupę stanowią pracownicy ze stażem pracy od 6 do 15 lat. Tylko $8 \%$ pracowników to osoby ze stażem pracy poniżej 2 lat.

Tabela 5. Struktura grupy badanych osób - staż pracy w badanym zakładzie pracy

\begin{tabular}{|l|r|r|r|r|r|r|}
\hline \multirow{2}{*}{ Staż pracy } & \multicolumn{2}{|c|}{ Ogółem } & \multicolumn{2}{c|}{ Kobiet } & \multicolumn{2}{c|}{ Mężczyzn } \\
\cline { 2 - 7 } & $\begin{array}{c}\text { Liczba } \\
{[100]}\end{array}$ & $\begin{array}{c}\% \\
{[100]}\end{array}$ & $\begin{array}{c}\text { Liczba } \\
{[12]}\end{array}$ & $\begin{array}{c}\% \\
{[12.00]}\end{array}$ & \multicolumn{1}{c|}{$\begin{array}{c}\text { Liczba } \\
{[88]}\end{array}$} & $\begin{array}{c}\% \\
{[88.00]}\end{array}$ \\
\hline do 2 lat & 8 & 8.00 & 2 & 2.00 & 6 & 6.00 \\
\hline od 3 do 5 lat & 19 & 19.00 & 1 & 1.00 & 18 & 18.00 \\
\hline od 6 do 10 lat & 27 & 27.00 & 5 & 5.00 & 22 & 22.00 \\
\hline od 11 do 15 lat & 30 & 30.00 & 4 & 4.00 & 26 & 26.00 \\
\hline od 16 do 20 lat & 16 & 16.00 & 0 & 0.00 & 16 & 16.00 \\
\hline powyżej 20 lat & 0 & 0.00 & 0 & 0.00 & 0 & 0.00 \\
\hline
\end{tabular}

Źródło: opracowanie własne

Na wykresie 2 zaprezentowano wyniki badań poziomu klimatu bezpieczeństwa dla pracowników $\mathrm{z}$ określonym stażem pracy w badanym zakałdzie pracy. Widzimy tu wyraźny wpływ kultury organizacyjnej przedsiebiorstwa na poprawę poziomu klimatu bezpieczeńśtwa. Pomimo, że pracownicy z najniższym stażem pracy osiągneli (w tych samych kategoriach) ponownie najniższy wynik, to jednak jest on wyższy od poprzedniego.

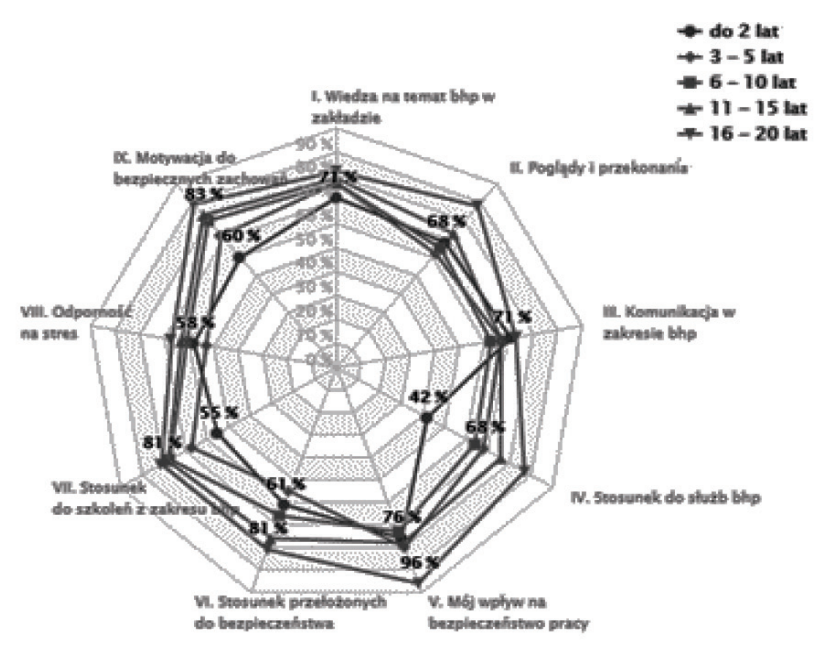

Wykres 2. Poziom klimatu bezpieczeństwa w zależności od stażu pracy pracownika w Źródło: opracowanie własne danym zakładzie pracy 


\section{WNIOSKI Z BADAŃ}

Wyniki badań dowodzą, ze czynniki socjodemograficzne oraz kultura organizacyjna przedsiębiorstwa mają wpływ na poziom klimatu bezpieczeństwa w przedsiębiorstwie.

Wykazano wpływ stażu pracy (zarówno ogólnego jak i w danym przedsiębiorstwie) na poziom klimatu bezpieczeństwa. Najniższy poziom klimatu bezpieczeństwa występuje wśród pracowników z najniższym stażem pracy (poniżej 2 lat). Pracownicy ci wykazują najniższy poziom klimatu bezpieczeństwa prawie we wszystkich kategoriach tematycznych. Takie wyniki skłaniają do podjęcia wzmożonych działań w zakresie szkoleń i działań prewencyjnych odnoście do tej grupy pracowników.

Zidentyfikowano także dwa najsłabsze punkty badanego przedsiębiorstw: Odporność na stres i Komunikację w zakresie bhp. Te dwie kategorie wypadły najsłabiej i to niezależnie od stażu pracy respondenta.

W badanym zakładzie na wysokim poziomie jest: Motywacja do bezpiecznych zachowań i świadomość pracowników co do ich wpływu na bezpieczeństwo.

Wyniki badań mogą posłużyć przedsiębiorstwu na ukierunkowanie swoich działań w zakresie podnoszenia bezpieczeństwa pracy na konkretne grupy pracowników.

\section{PODSUMOWANIE}

Przedsiębiorstwa coraz lepiej rozumieją (czują) potrzebę wprowadzania Zintegrowanego Systemu Zarządzania. Wprowadzane systemy zarządzania poszczególnymi elementami przedsiębiorstwa często dobywają się $\mathrm{W}$ sposób nieformalny. Związane jest to z kosztami związanymi z audytami i certyfikowaniem tych systemów. Takie koszty to duże obciążenie, zwłaszcza dla małych przedsiębiorstw. Jednak przedsiębiorstwa, a zwłaszcza kadra zarządzająca, powinna zdawać sobie sprawę z korzyści jakie daje wprowadzania formalnych lub nieformalnych zasad zarządzania. Tym bardziej, że bezpieczeństwo pracy wpływa na wszystkie aspekty działalności gospodarczej człowieka. Praca bez wypadków wpływa zarówno na jakość wyrobów jak i na jakość środowiska. A zapewnienie bezpieczeństwa pracy często bardziej zależy od postaw pracowników, ich przekonań i poglądów. Zmiana nastawienia pracownika do bezpieczeństwa nie musi wiązać się w dużymi nakładami, ale jest procesem długotrwałym, wymagającym od pracodawcy ciągłych (stałych) działań, które staną się „filozofią życia” a nie jednorazową akcją w celu zapewnienia bezpieczeństwa pracownikom. 


\title{
LITERATURA
}

A review of safety culture and safety climate literature for the development of the safety culture inspection toolkit, (2005) Research Report 367, Prepared by Human Engineering for the Health and Safety Executive, s.4

Dudkiewicz W., (2000) Podstawy metodologii badań do pracy magisterskiej i licencjackiej z pedagogiki, Wydawnictwo Stachurski, Wyd. 4 rozsz., Kielce.

Franksoft-Nachmias C., (2001), Metody badawcze w naukach spotecznych, Wydawnictwo Zysk i S-ka, Poznań.

Gabryelewicz I., Krupa P., Sadłowska - Wrzesińska J. (2015), IT tool for aiding assessment of safety culture level in an organization, Applied Mechanics and Materials, Vol.795, s. 77-83, DOI: 10.4028/www.scientific.net/AMM.795.77.

Gabryelewicz I., Sadłowska - Wrzesińska J., Kowal E.,(2015), Evaluation of safety climate level in a production facility, Procedia Manufacturing: 6th International Conference on Applied Human Factors and Ergonomics (AHFE 2015) and the Affiliated Conferences, AHFE s. 6211-6218.

Kaczmarczyk S., (2003), Badania marketingowe. Metody i techniki, Polskie Wydawnictwo Ekonomiczne, Warszawa.

Kisiel P., (2000), Społeczne aspekty badań marketingowych. Wybrane problemy, Akademia Ekonomiczna w Krakowie, Kraków.

Konarzewski, K., (2000), Jak uprawiać badania oświatowe : metodologia praktyczna. Wydawnictwa Szkolne i Pedagogiczne Spółka Akcyjna, Warszawa.

Łobocki M., (2004), Wprowadzenie do metodologii badań pedagogicznych, Oficyna Wydawnicza Impuls, Kraków.

Mangione T.W., (1999), Ankietowanie pocztowe $w$ badaniach marketingowych $i$ socjologicznych, Wydawnictwo Naukowe PWN, Warszawa.

Pilch T., Bauman T., (2001), Zasady badań pedagogicznych, strategie ilościowe i jakościowe, Wydawnictwo Akademickie „Żak”, Wyd. 2, Warszawa.

Sołoma L., (2002), Metody i techniki badań socjologicznych, Wydawnictwo Uniwersytetu Warmińsko-Mazurskiego, Olsztyn.

Zaczyński W., (1995), Praca badawcza nauczyciela, Wydawnictwo Szkolne i Pedagogiczne, Warszawa.

\section{SURVEY RESEARCH AS A FACTOR SUPPORTING SAFETY WORK MANAGEMENT}

\begin{abstract}
According to statistical data, the main cause of accidents is improper behaviour of employees. Analyses of reasons of accidents mention a low level of the labour safety culture. In order to increase the safety culture it is obligatory to diagnose the enterprise condition and to identify weak and strong sides of the organisation. To achieve this aim, a good diagnostic tool is necessary, e.g. a survey. The article presents the rule of creating surveys, a proposal of such survey and partial research results obtained by the means of such survey for analysing the level of the safety climate at enterprises.
\end{abstract}

Keywords: survey research, safety work, safety culture 
